\title{
Melatonin, Mitochondria and Successful Aging
}

\author{
Idowu Abimbola John* \\ Department of Physiology, Lagos State University College of Medicine, Nigeria
}

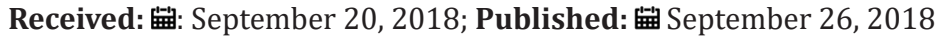

*Corresponding author: Idowu Abimbola John, Department of Physiology, Lagos State University College of Medicine, 1-5 Oba Akinjobi Way GRA, Ikeja, Lagos, Nigeria

\section{Abstract}

Although melatonin has been shown to be involved in the aging process and as a therapeutic target during normal aging, it is yet to be widely accepted as a therapeutic target for age related vulnerabilities. With more evidences being unraveled from different studies, important lifestyle changes that will optimize its normal synthesis could be beneficial for the human population.

\section{Introduction}

Aaron Lerner and colleagues discovered melatonin in 1958 and the chemical structure was described in 1959 as N-acetyl5-methoxytryptamine [1]. Melatonin is endogenously produced majorly in the pineal gland especially at night. Melatonin is one of the strongest antioxidants known; it scavenges hydroxyl and peroxyl radicals $[2,3]$. Melatonin has a strong relationship with aging, the loss of melatonin in old age may contribute to the severity and incidence of neurodegenerative diseases such as Alzheimer's disease [4]. Armstrong and Redman in 1991 suggested that melatonin might have beneficial effects in aging because of its association with the circadian timing system [5]. At advanced age melatonin is lost and leads to disturbances in the circadian pacemaker, which causes internal desynchronization and deterioration of health. Hence, melatonin has been used to treat jet lag symptoms as well as phase shift the circadian clock [6]. This is also validated by the presence of melatonin receptors on the suprachiasmatic nucleus [7]. Although, melatonin has been used to treat jet lag and insomnia, it is yet to be widely accepted as a therapeutic target for successful ageing despite the convincing evidences. In here, it is suggested that lifestyle be adjusted to allow body to maximize the natural synthesis of melatonin.

\section{Mitochondria, Mitochondrial Biology and Implication in Aging}

The mitochondria produce ATP through oxidative phosphorylation by the respiratory chain complexes I, II, III, and IV and ATP synthase, V [8]. The proton gradient across the inner mitochondrial membrane is used for ATP production via ATP synthase, Complex V $[8,9]$. The mitochondria play an important role in the aging process; respiratory chain dysfunction, formation of reactive oxygen species, damage of mitochondrial proteins or lipids and mitochondrial DNA damage [10-13]. In relation to increasing age, there is a direct correlation of reactive oxygen species and oxidative damage of DNA, proteins and lipids [14]. Mitochondrial defects associated with aging have been observed in skeletal muscle and the brain, which are high-energy demanding tissues, which depend on oxidative phosphorylation [15].

\section{Implication on Successful Aging}

Melatonin plays a significant role in modulating organelle, cell and system function. Among compounds that have been tested as a therapeutic agent for age related vulnerabilities, melatonin has been shown to be the most potent. It has been used as a therapeutic target in cardiovascular, reproductive, neurodegenerative, sleep, memory and microbial studies. Recently, it was discovered that melatonin is able to regulate mitochondria membrane potential to optimize ATP production in middle age and old mitochondria isolated from cortical neurons in mice [16]. Despite the implication of melatonin in many age-related abnormalities, it is presently not widely accepted as a therapeutic agent for successful aging. Successful aging in this context meaning growing older without vulnerability to age related disease or loss of normal function. While this is due partly to the lack of longevity studies in humans, it is important to recommend on the basis of supporting evidences from animal experiments, that the natural production of melatonin in the human body should be optimized.

This can be achieved by sleeping in dark rooms at night. This is because melatonin synthesis is sensitive to light, which is why melatonin levels are at the highest levels at night. Alongside this, the circadian rhythm should not be altered for too long unnecessarily. Melatonin levels in the blood are at the peak between 2:00am and 4:00am in the morning. In order to gain the maximum benefit from this important therapeutic molecule, it is believed that sleep occurring between 11:00pm and 5:00am will aid this process. 
Hence, adjusting the sleep time at night in a dark room to create the appropriate conditions for the body to maximally synthesize and release melatonin could help human population age successfully.

\section{References}

1. Lerner AB, Case JD, Heinzelman RV (1959) Structure of melatonin. J Am Chem Soc 81: 6084-6090.

2. Pieri C, Marra M, Moroni F, Recchioni R, Marcheselli F (1994) Melatonin: a peroxyl radical scavenger more effective than vitamin E. Life Sciences 55(15): 271-276

3. Reiter RJ (1995) The pineal gland and melatonin in relation to aging: $\mathrm{A}$ summary of the theories and of the data. Exp Gerontol 30(3-4): 199-212.

4. Reiter RJ (1998) Oxidative damage in the central nervous system: protection by melatonin. Progr Neurobiol 56(3): 359-384.

5. Armstrong SM, Redman JR (1991) Melatonin: a chronobiotic with antiaging properties? Med Hypothesis 34(4): 300-309.

6. Skene DJ, Lockley SW, Arendt J (1999) Melatonin in circadian sleep disorders in the blind. Biol Signals Recept 8(1-2): 90-95.

7. Wu YH, Ursinus J, Zhou JN, Scheer FA, Ai-Min B, et al. (2013) Alterations of melatonin receptors MT1 and MT2 in the hypothalamic suprachiasmatic nucleus during depression. Journal of affective disorders 148(2-3): 357367.

8. Bratic A, Larsson N (2013) The role of mitochondria in aging. The Journal of Clinical Investigation 123(3): 951-957.

ISSN: 2574-1241

DOI: 10.26717/BJSTR.2018.09.001788

Idowu Abimbola John. Biomed J Sci \& Tech Res

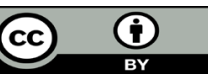

This work is licensed under Creative Commons Attribution 4.0 License

Submission Link: https://biomedres.us/submit-manuscript.php
9. Perry SW, Norman PJ, Barbieri J, Brown BE, Gelbard HA (2011) Mitochondrial membrane potential probes and the proton gradient: a practical usage guide. Biotechniques 50(2): 98-115.

10. Harman D (1972) The biologic clock: the mitochondria? J Am Geriatr Soc 20(4): 145-147.

11. Paradies G, Petrosillo G, Paradies V, Reiter RJ, Ruggiero FM (2010) Melatonin, cardiolipin and mitochondrial bioenergetics in health and disease. J Pineal Res 48(4): 297-310.

12. Paradies G, Petrosillo G, Paradies V, Ruggiero FM, (2010) Oxidative stress, mitochondrial bioenergetics, and cardiolipin in aging. Free Radic Biol Med 48: 1286-1295.

13. Paradies G, Petrosillo G, Paradies V, Ruggiero FM (2011) Mitochondrial dysfunction in brain aging: Role of oxidative stress and cardiolipin. Neurochemistry International 58(4): 447-457.

14. Stadtman ER (1992) Protein oxidation and aging. Science 257(5074): 1220-1224.

15. Li H, Sharma L, Li Y, Hu P, Idowu A, et al. (2013) Comparative bioenergetic study of neuronal and muscle mitochondria during aging. Free Rad Biol Med 63: 30-40.

16. Idowu AJ, Sharma LK, Bai Y, Reiter RJ (2017) Melatonin modulates neuronal mitochondria function during normal ageing mice. Niger J Physiol Sci 32(2): 145-152.

$\begin{array}{ll}\text { BIOMEDICAL } & \text { Assets of Publishing with us } \\ \text { RESEARCHES } & \text { - Global archiving of articles } \\ & \text { - Immediate, unrestricted online access } \\ & \text { - Rigorous Peer Review Process } \\ \end{array}$

